\title{
Epigastric Pain in Acute Renal Infarction: the Forgotten Presentation
}

\author{
Ossama Maadarani, Zouheir Bitar \\ Internal medical department, Ahmadi Hospital- Kuwait oil company, Al Ahmadi, Kuwait
}

Doi: 10.12890/2015_000170 - European Journal of Case Reports in Internal Medicine - ๑ EFIM 2015

Received: 03/12/2014

Accepted: 20/12/2014

Published: $12 / 01 / 2015$

How to cite this article: Maadarani O, Zouheir B. Epigastric pain in acute renal infarction: the forgotten presentation. EJCRIM 2015;2:doi: 10.12890/2015_000170

Conflicts of Interests: The authors declare that they have no conflicts of interest in this research

This article is licensed under a Commons Attribution Non-Commercial 4.0 License

\section{ABSTRACT}

Epigastric pain is a manifestation of several medical and surgical conditions. However, when persistent epigastric pain is associated with microscopic or frank haematuria and elevated lactate dehydrogenase (LDH), especially in patients with increased risk of thromboembolic events, acute renal infarction (ARI) should be considered. We report the case of a 77-year-old male patient who presented with sudden persistent epigastric pain and elevated LDH who was found to have atrial fibrillation. The patient was diagnosed with ARI. ARI is not usually a typical differential diagnosis in patients with persistent epigastric pain and elevated LDH in whom the risk of thromboembolic events is high. Thus, physicians should perform a contrast-enhanced CT scan as early as possible to rule out or confirm renal infarction.

\section{LEARNING POINTS}

- In acute kidney infarction, epigastric pain can be one of the clinical manifestations.

- The combination of unexplained epigastric pain and elevated lactate dehydrogenase and haematuria in a patient with an increased risk of thromboembolic events should raise the suspicion of acute kidney infarction.

- The physician should perform a contrast-enhanced CT scan as early as possible to rule out or confirm kidney infarction.

\section{KEYWORDS}

Epigastric pain, atrial fibrillation, lactate dehydrogenase

\section{INTRODUCTION}

The clinical manifestations of acute renal infarction (ARI) usually mimic those of other, more common, entities. As the symptoms and laboratory findings are nonspecific, the diagnosis of ARI requires a high degree of clinical suspicion and a low threshold for performing early contrast-enhanced CT scans (Fig. 1), especially in patients with an increased risk of thromboembolic events.

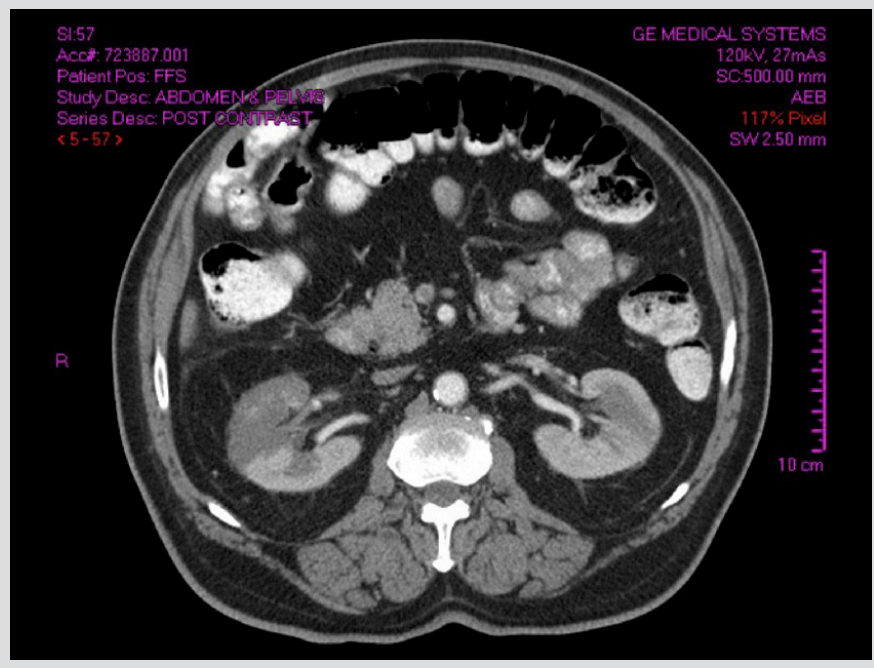

Figure 1: Contrast-enhanced computed tomography of the abdomen and pelvis showing right renal infarction. 


\section{CASE HISTORY}

A 77-year-old man presented with sharp epigastric pain that had started suddenly a few hours prior and moderate vomiting. The patient had a significant medical history for diabetes mellitus type II, hypertension and prostate enlargement. He never smoked or abused alcohol. The patient's blood pressure was $160 / 90 \mathrm{mmHg}$ and had an irregular pulse of 95 beats per minute, respiration rate of 20 breaths per minute and a temperature of $37.8^{\circ} \mathrm{C}$. Physical examination revealed an irregular heartbeat and tenderness in an epigastric area. The rest of the exam was unremarkable.

Laboratory tests revealed a haemoglobin value of $15 \mathrm{~g} / \mathrm{dl}$, leukocyte count of $13,000 / \mathrm{mm}^{3}$, neutrophils $80.5 \%$, platelets $260,000 / \mathrm{mm}^{3}$, serum

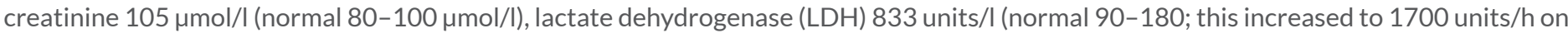
the next day), aspartate aminotransferase 168 units/I (normal 10-42) and alanine aminotransferase 100 units/I (10-40). Urinalysis was positive for blood, and urine protein was $250 \mathrm{mg} / \mathrm{dl}$. Three sets of cardiac enzymes were normal.

The patient's electrocardiography showed atrial fibrillation. Echocardiogram revealed a dilated left atrium, normal ejection fraction and no evidence of a thrombus or vegetation. The abdominal ultrasound showed no evidence of gallbladder disease.

Contrast-enhanced computed tomography (CECT) of the abdomen and pelvis showed a right renal infarction.

The patient was anti-coagulated with heparin and warfarin. His symptoms were significantly improved, and he was discharged.

\section{DISCUSSION}

ARI can be a serious medical emergency. The exact incidence of ARI is not known because the diagnosis is usually missed. In one study, the incidence of kidney infarction in patients with atrial fibrillation was approximately $2 \%{ }^{[1]}$.

The most common source of renal emboli is a diseased heart ${ }^{[2]}$. Atrial enlargement secondary to valvular heart disease or a dyskinetic left ventricle after myocardial infarction can provide the source of mural thrombi that may dislodge and become renal artery emboli ${ }^{[2]}$.

Hazanov et al. reported 44 cases of renal infarction secondary to atrial fibrillation ${ }^{[3]}$. In a study containing 27 patients diagnosed with ARI, cardiac disease was found in 11 patients (41\%), 10 of whom had documented atrial fibrillation. In the other 16 patients, the aetiology of ARI was considered to be idiopathic. Different thrombophilic abnormalities were found between the patients in the idiopathic group.

Hyperhomocysteinaemia was detected in five patients; one had protein $\mathrm{S}$ deficiency, one had a factor $\mathrm{V}$ Leiden mutation and one had antithrombin deficiency ${ }^{[4]}$.

The clinical presentations of ARI are non-specific and may be confused with other entities. ARI patients commonly present to an emergency department with flank pain associated with fever, nausea, vomiting and/or acute onset hypertension ${ }^{[5]}$.

An abrupt onset of abdominal or flank pain, along with nausea and vomiting, was found in approximately $50 \%$ of patients in a study conducted by $\mathrm{Chu}$ and colleagues. In the same study, $30 \%$ of patients reported fever. Elevated white blood cell count and LDH were noticed in a blood analysis of the patient with ARI. Urinary analysis revealed haematuria and proteinuria ${ }^{[6]}$.

Imaging is the key to diagnosing renal infarction. The diagnosis can be confirmed by CECT, angiography or isotope scan. The sensitivity of CECT is $80 \%$, that of renal isotope is $97 \%$ and that of angiography is $100 \%{ }^{[3]}$. The absence of contrast in the affected renal tissue is best demonstrated by $\mathrm{CT}^{[2]}$. Smaller infarcts are observed as wedge-shaped, low-density areas within an otherwise normal appearing kidney (partial kidney infarction). Complete kidney infarction is identified by a non-enhanced kidney with a cortical rim sign, i.e., the outer 2-4 mm are enhanced due to perfusion by the capsular branches ${ }^{[2]}$.

The differential diagnosis of ARI includes renal colic, pyelonephritis, biliary colic, acute cholecystitis and other thromboembolic events, such as mesenteric ischaemia and splenic infarction ${ }^{[7]}$.

Optimal treatment modalities for ARF have not been evaluated in large prospective studies because of the rarity of this condition ${ }^{[8]}$. In 1973 , a comparison between surgical and medical management for unilateral renal embolism showed favour towards conservative therapy.

Anticoagulation with or without thrombolysis is considered to be the primary treatment strategy for ARI ${ }^{10]}$.

Timing is important when considering thrombolytic therapy as a treatment option for ARI. ARI should be diagnosed within the first $4 \mathrm{~h}$ after symptom onset to ensure the feasibility of using thrombolysis with intra-arterial urokinase ${ }^{[11]}$.

Ideally, ARI should be diagnosed within the first 90 min of symptom onset ${ }^{[12]}$, a situation that rarely occurs ${ }^{[13,14]}$. Many studies have reported favourable results using anticoagulants (unfractionated heparin, low-molecular-weight heparin and warfarin) in the treatment of ARI ${ }^{[3,13]}$. For patients with total parenchymal involvement due to bilateral emboli or for those with a unilateral main renal artery embolus in a solitary kidney, surgical embolectomy remains the only treatment option, although it is rarely performed ${ }^{[13,14]}$.

In our case, the patient presented with unexplained persistent epigastric pain, which could have been due to a number of reasons. However, the combination of elevated LDH, which doubled the next day, mild elevation of aminotransferase, blood in the urine and the presence of atrial fibrillation as a marker of increased risk of thromboembolic events raised the suspicion of a thromboembolic manifestation, which was confirmed by a CECT scan.

\section{CONCLUSION}

Persistent epigastric pain can be a manifestation of ARI. In combination with elevated LDH, especially in patients with an increased risk of thromboembolic events, a CECT scan should be performed as early as possible to rule out or confirm renal infarction. 


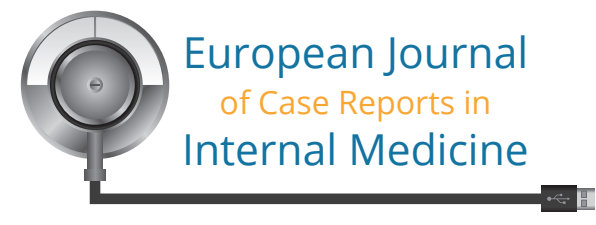

\section{REFERENCES}

1. Frost L, Engholm G, Johnsen S, Moller H, Henneberg EW, Husted S. Incident thromboembolism in the aorta and the renal, mesenteric, pelvic, and extremity arteries after discharge from the hospital with a diagnosis of atrial fibrillation, Arch Intern Med 2001;161:272-276.

Dunnick R, Sandler CM, Newhouse JH. Vascular diseases, in Textbook of Uroradiology, 5th ed. Philadelphia: Lippincott Williams \& Wilkins, 2013, p. 182.

3. Hazanov N, Somin M, Attali M, Beilinson N, Thaler M, Mouallem M et al. Acute renal embolism. Forty-four cases of renal infarction in patients with atrial fibrillation, Medicine (Baltimore) 2004;83:292-299 4. Bolderman R, Oyen R, Verrijcken A, Knockaert D, Vanderschueren S. Idiopathic renal infarction, Am J Med 2006;119:356.e9-12

5. Traube L. Üeber den Zusammenhang von Herz- und Nierenkrankheiten [The Relationship between Cardiac and Renal Diseases. Berlin: August Hirschwald, 1856 p. 77.

6. Chu PL, Wei YF, Huang JW, Chen SI, Chu TS, Wu KD. Clinical characteristics of patients with segmental renal infarction, Nephrology (Carlton) 2006;11:336-340

7. Nasser NJ, Abadi S, Azzam ZS. Acute renal infarction from a cardiac thrombus, Nat Clin Pract Nephrol 2007:3:631- 635.

Kasser NJ, Abadi S, Azzam ZS. Acute renal infarction from a cardiac thrombus, Nat Clin Pract Nephrol 2007;3:631- 635.

9. Taylan I, Sar F, Kazancioglu R, Tuqrul M, Caymaz M, Tatli E. Embolic segmental renal infarction in a patient with atrial fibrillation, Hong Kong J Nephrol 2006;8:40.

10. Huang CC, Kao WF, Yen DH, Huang HH, Huang Cl, Lee CH. Renal infarction without hematuria: two case reports, J Emerg Med 2006;30:57-61.

11. Korzets Z, Plotkin E, Bernheim J, Zissin R. The clinical spectrum of acute renal infarction, Isr Med Assoc J 2002;4:781-784.

12. Blum U, Billmann P, Krause T, Gabelmann A, Keller E, Moser E. Effect of local low-dose thrombolysis on clinical outcome in acute embolic renal artery occlusion, Radiology 1993;189:549-554.

13. Tsai SH, Chu SJ, Chen SJ, Fan YM, Chang WC,Wu CP et al. Acute renal infarction: a 10-year experience, Int J Clin Pract 2007;61:62-67.

14. Nicholas GG, DeMuth WE Jr. Treatment of renal artery embolism, Arch Surg 1984;119:278-281. 